\title{
Influence of the School on Langauge Acquistion and Development tin the light of Pre- Primary school Children in Mathira East District, Kenya
}

\author{
Leah. M. Njiru \\ School of Education, Mount Kenya University \\ Email: leahnjiru2030@gmail \\ Maina Moses N. \\ School of Education, Mount Kenya University \\ mainamosesn@gmail.com \\ Samuel. W. Kaniaru \\ School of Education, Mount Kenya University \\ kaniarusamuel@yahoo.com
}

Doi:10.5901/mjss.2014.v5n5p

Abstract

The problem of the Kenyan pre- primary school pupils can be seen or heard in various media outlets. Schools in urban areas seem favored compared to those in rural areas. Urban areas attract better social amenities and therefore better employees making them receive better quality teachers. The support for pre-primary schools, by the government is very little. In most urban areas parents have higher incomes, can afford books and children are cultured speaking other languages unlike the rural areas where the children first learn their mother tongue. The schools in rural areas teach other languages like English and Kiswahili as a second language. The learning as a second language compounded with lack of adequate resources and illtrained teachers make it more difficult for pre- primary school going children to learn language competencies.

Keywords: Education, School, Language, Chidlren, Learning

\section{Introduction}

Pre-Primary school education in developing countries is considered of great importance because of its wide range of benefits. These include the shaping and strengthening of the child as an individual in relation to his or her fellow people, to nature, and to the world as an environment. Primary schooling is thought also to build a capacity for lifelong learning in individuals, and to develop knowledge, skills and attitudes which will contribute to the general development of the community in which individuals live by meeting manpower needs and improving community life. Children have different learning styles that are reflected in different academic strengths, weaknesses, skills, and interests.

Roberts (1998) notes teaching Language to young learners in the primary stage requires knowledgeable teachers who are able to deal with children. Here, sufficient exposure in psychology is considered necessary since young learners have special learning styles and, accordingly, special teaching methods that evoke their mentalities by turning abstracts into tangibles and ideas into actions. The primary stage is the foundation that supports the higher grades. Very critical and creative primary English language teachers are strongly looked-for to be responsible for the future leaders.

The language skills needed to build the foundation of reading and writing fall into different clusters (Snow \& Dickinson 1991). Some skills are required to carry on informal conversations with friends and relatives. What's typical of these interactions is that people understand the meaning of the interaction largely because the ongoing activity makes clear what they are talking about. Another cluster of language skills is needed when people must make sense of words without all these immediate supports.

Knowing the "right word" is vital if the child is to communicate information clearly. Large vocabularies have long been known to be linked to reading success (e.g., Anderson \& Freebody 1981); they also are a signal that children are building the content knowledge about the world that is so critical to later reading (Neuman 2001). 


\section{Methodology}

Questionnaires were the main tool of data collection. There are several advantages associated with questionnaires. One advantage associated with questionnaires in that data collected can be stored for future reference. Similarly, participants find more convenient to fill questionnaires which saves on time. Questionnaire development was based on the research questions above.

To see what effect these preschool interactions and experiences had on literacy development. The researchers assessed the children's ability to understand words, their ability to produce narratives, and their emergent literacy skills, including letter knowledge, early reading and writing, and phonetic awareness.

Once the questionnaires were collected, they were scrutinized to ensure they are duly completed and are consistent, after which they were numbered. This was followed by checking that all questions were answered according to instructions to reduce errors and maintain the validity of the data. The data was analyzed using SPSS. The means, bar charts and inferential statistics were used for presentation.

\section{Review of Literature}

\subsection{Rural and Urban Area Schools}

Even today, many people assume that urban and rural areas have their own distinct cultures and concerns that affect their priorities and needs. Terms like "modern" and "traditional" are supposed to be qualities that are exclusive to one group but not to the other. This is also entirely untrue.

As student and family diversity has increased, so has the number of teachers who leave the profession (BrownJeffy \& Cooper, 2011). Researchers have noted that challenges for new teachers in rural schools may be compounded by lack of resources, and by limited opportunities for meaningful professional development in rural areas (Burton \& Johnson, 2010; Wenger \& Dinsmore, 2009). While student and community diversity has increased, data suggest that there is not a proportionate increase in the diversity of the teaching force, particularly in rural areas (Burton \& Johnson, 2010).

Educational and other research today finds that it is no longer appropriate or useful to define urban in terms of rural or the other way around. To do so is to create a competitive relationship between them, to the disadvantage of rural areas. Such thinking also generalizes situations that are actually very different from each other. Furthermore, a "one size fits all" approach to policy and its implementation makes it possible to overlook and disregard important aspects of the lives and the needs of communities.

The realities faced by people in rural areas cannot always be addressed by policy made elsewhere and for everyone. One distressing legacy of past policy is that rural areas are usually presented in negative terms. This is largely due to the miserable conditions under which people had to live in those grim former homelands. The majority of time at school is spent with teachers, so they are influential role models. In many rural schools in developing countries, there are no books (for Kenya.Mungai, 2002), in which case the role of the teacher becomes extremely important.

Like many social generalisations, this description contains some bitter truths, but it is far from complete. Rural communities have achieved hard won methods of managing their affairs, and each rural community has developed sophisticated social networks and cultural practices. Most villages have some televisions and cell phones, and a proportion of people who live there work in towns and return over weekends, so creating much interchange between village and town.

Conditions in rural areas still have many shortcomings despite their potential, and that the conditions of poverty and under-development are reflected in the quality of education available there.

The achievement of real quality in education in rural areas will only come about when there is significant social and economic development in those areas. Until then, the education provided in rural areas will limit people's opportunities to lead long, healthy and creative lives, or to acquire knowledge and enjoy freedom, dignity and self-respect. Villages and rural communities are difficult to reach, the physical conditions in schools are inadequate, and learner performance in comparison to schools elsewhere is weak

\subsection{Attainment of Language Competencies}

Languages are not only about getting something done or for reaching a specific goal. They carry cultural loads and histories, and they shape how people think and understand the world. It is important for pre-primary school children to 
keep current language in- education to maintain the home language (also referred to as the mother tongue) while providing access to the effective use of at least one additional language.Most children in Kenya are taught in their mother tongue at the beginning of their formal schooling and then they switch to a different language of learning and teaching in Class 4. That different language is usually English.

English is seen as a door to certain kinds of further education, employment and privileged status. Many people, including those in rural areas, want to learn English and be fluent in it. However, given the high levels of illiteracy among adults and the infrequent exposure to languages like English at fluent and competent levels, rural children have little opportunity to live, think and work in a language environment beyond that of their mother tongue (Taylor and Mulhall, 2001). It is very important, however, that all learners, including rural and urban children, acquire deep skills in one language, before proceeding to learn another. This is not intended to confine them in a language trap. However, unless the first language is learned very well, people are likely to have very limited and limiting linguistic abilities in whatever language they seek to use in their lives (Brodie et al, 2002).

The absence of a reading culture in rural communities is very worrying. Information in printed form is difficult to come by - there are very few books or magazines or newspapers in homes or elsewhere, and there are usually no libraries. (Hedges, 2000)And questions remain about the language competence of many teachers in rural schools. Therefore, the language environment in rural areas may be rich in one or two languages, but that richness is part of a particular lifestyle which may not include much that is contemporary and modern. Language ability is dependent upon meeting challenges and finding ways of speaking, reading and writing about the well-known, the new and the unusual. An environment that does not make such demands cannot promote language development. Rural primary schools face particular disadvantages, some of which stem from national educational programmes which are geared more closely to an urban context. spoken language skills of children reared in poverty are depressed in comparison with the general population, and in comparison with their general cognitive abilities. Hoff (2003b)

High drop-out rates are common; these are due to pupil-related, school-related, constructed or macro-system factors. Although some generalisations can be made, research shows that the constraints depend on the specific environment in which a school is located. Efforts have been made to address these problems by reviewing teacher training programmes, introducing curriculum reform and developing new approaches to school organisation, but these changes tend to be piecemeal.

\subsection{The General Objectives of Language Activities}

According to the Ministry of Education Science and Technology, who set the syllabus that includes language activities, Language enables children to express themselves and satisfy their needs. Through language they communicate their feelings to others as they interact with them. During the early years of life, children develop oral, reading and writing which are important in language development.

Oral skills include listening and speaking skills which are essential for reading and writing readiness skills. Listening and speaking skills are acquired before other language skills. Reading skills involve training children to observe and interpret details in pictures, objects or symbols. Writing is an important skill for communication. Children should be given writing readiness activities to prepare them for actual writing. Activities should be designed to prepare them physically and also enable them to develop ideas and concepts to write about. The general objectives of the language activities course should be able to;

- Improve listening ability, concentration, understanding and memory

- Develop vocabulary

- Express themselves freely and confidently

- Speak clearly and fluently

- Use acceptable speech habits

- Appreciate and use their mother tongue

- Look at and interpret details in objects, pictures, symbols and signs

- Recognize and name basic colours and shapes

- Develop eye hand coordination

- Develop interest in books

- Use basic tools for writing and drawing

- Reason and think logically

- Read simple words 


\section{Research Results Discussion and Analysis}

\subsection{Demographic Characteristics of the Respondents}

Table 1 shows the questionnaire return rate. The questionnaires completed and returned were from 20 pre- primary school teachers. The rural schools were more than the urban schools because there are only three public- urban schools in Mathira East District of Nyeri County. The questionnaires return rate was 100\%.

Table 1: The Return Rate

\begin{tabular}{cccc}
\hline Respondents & Expected & Returned & Return rate \\
\hline Pre- primary school teachers & 20 & 20 & $100 \%$ \\
\hline
\end{tabular}

\subsection{Gender of the Respondents}

Figure 1 shows the composition of respondents by sex in the schools that were sampled. 100\% of the respondents who returned the questionnaires were all female.

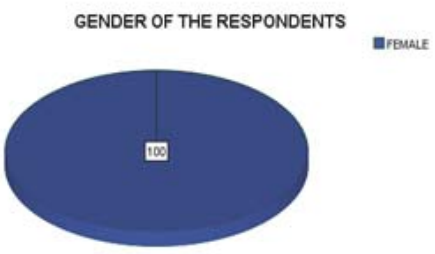

The research findings were interesting given that all the pre-primary schools sampled had female teachers. This could easily cause an issue when it comes to effective gender socialization of pre-primary children.

\subsection{Age of Respondents}

Figure 2 is the respondents' age, the respondents were asked to fill in their ages and not the age distribution.

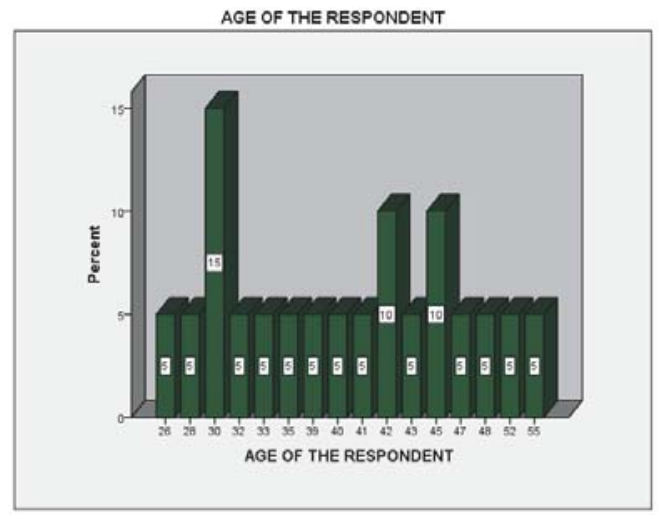

The ages of most teachers are chronologically on the high side. They can therefore be taken to be mature. $15 \%$ of the respondents were aged 30 years, $10 \%$ of the respondents were aged 42 and 45 years, and all other respondents had an equal distribution of $5 \%$ each aged 26 years, 28 years, 32 years, 33 years. 35 years, 39 years, 40 years, 43 years, 47 years, 48 years, 52 years and 55 years.

\subsection{Education Qualification of Respondents}

The researcher sought to find out how qualified the teachers teaching pre- primary schools were qualified. The responses are displayed in figure 3. 


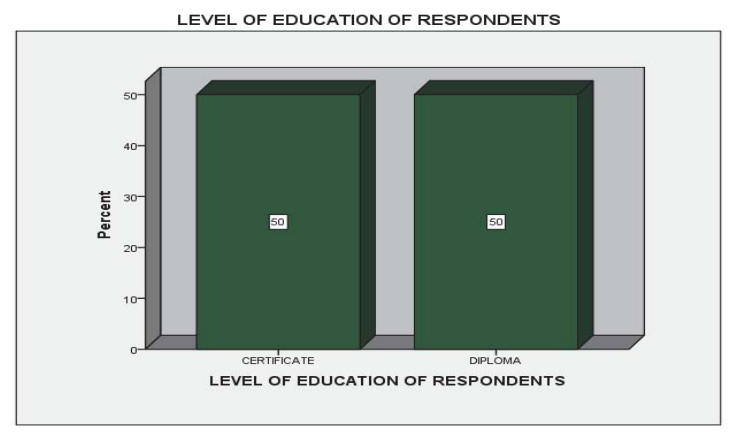

Figure 3 shows that, the 20 questionnaires returned, $50 \%$ of the respondents had certificate qualification while $50 \%$ had a diploma qualification.

\subsection{The Type of School the Respondents Taught}

The researcher sought to find out the type of school the respondents taught. The schools were either public urban or public rural.

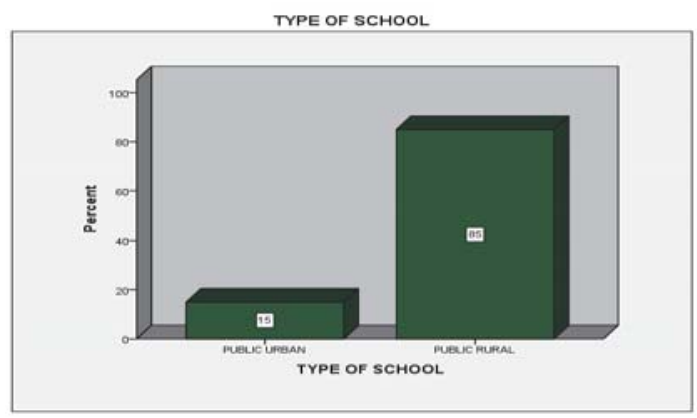

As displayed in Figure 4, 15\% of the respondents taught in public urban schools while $85 \%$ of the respondents taught in public rural schools.

\subsection{The Competencies which can be performed by students in percentage}

The results are displayed in Table 3 and table 4 the various competencies according to the set objectives by the MoEST (Ministry of Education Science and Technology)

Table 3:

\begin{tabular}{|l|c|c|c|c|c|c|c|}
\hline & $\begin{array}{c}\text { Total } \\
\text { enrolment }\end{array}$ & $\begin{array}{c}\text { Children who can } \\
\text { listen and tell } \\
\text { simple stories }\end{array}$ & $\begin{array}{c}\text { Children who } \\
\text { can news tell }\end{array}$ & $\begin{array}{c}\text { Children who can } \\
\text { solve simple } \\
\text { riddles }\end{array}$ & $\begin{array}{c}\text { Children who can } \\
\text { listen to and repeat } \\
\text { tongue twisters }\end{array}$ & $\begin{array}{c}\text { Children who can } \\
\text { describe daily } \\
\text { routines }\end{array}$ & $\begin{array}{c}\text { Children who can } \\
\text { describe daily } \\
\text { events }\end{array}$ \\
\hline N Valid & 20 & 20 & 20 & 20 & 20 & 20 & 20 \\
Sum & 834 & 557.00 & 612.00 & 359.00 & 386.00 & 630.00 & 568.00 \\
percentage & - & $68 \%$ & $73.38 \%$ & $43 \%$ & $46.2 \%$ & $75.53 \%$ & $68.1 \%$ \\
\hline
\end{tabular}

As evidenced in table $3,68 \%$ of the children can listen and tell simple stories, $73 \%$ of the children can tell news, $43 \%$ of the children can solve simple riddles, $46.2 \%$ of the respondents can listen to and repeat tongue twisters, $75.53 \%$ of the respondents can describe daily routines, $68.1 \%$ of the children can describe daily events.

The children seem to be performing fairly well in several competencies and face challenges in solving simple riddles. 
Table 4:

\begin{tabular}{|l|c|c|c|c|c|}
\hline & $\begin{array}{c}\text { Total } \\
\text { enrolment }\end{array}$ & $\begin{array}{c}\text { Children who can read } \\
\text { letters from left to right }\end{array}$ & $\begin{array}{c}\text { Children who can interpret and } \\
\text { describe details in pictures }\end{array}$ & $\begin{array}{c}\text { Children who can } \\
\text { group objects }\end{array}$ & $\begin{array}{c}\text { Children who can ask and } \\
\text { answer simple questions }\end{array}$ \\
\hline N Valid & 20 & 20 & 20 & 20 & 20 \\
Sum & 834 & 612.00 & 618.00 & 634.00 & 597.00 \\
Percentage & - & $73 \%$ & $74 \%$ & $76 \%$ & $71.58 \%$ \\
\hline
\end{tabular}

As shown in Table $4,73 \%$ of the children can read letters from left to right, $74 \%$ of the children can interpret and describe details in pictures, $76 \%$ of the children can group objects, $71 \%$ of the respondents can ask and answer simple questions

\subsection{A Test for Significance of the Type of School on Attaining Language Competencies}

- $\quad H_{0}$ : There is no significant influence of type of school on learning language competencies in pre-primary school children.

- $\quad H_{1}$ : There is a significant influence of the type of school on learning language competencies in pre- primary school children.

\begin{tabular}{|c|c|c|c|c|c|c|}
\hline & \multirow{2}{*}{$\mathrm{t}$} & $\mathrm{df}$ & $\begin{array}{c}\text { Sig. (2- } \\
\text { tailed) }\end{array}$ & Mean Difference & \multicolumn{2}{|c|}{ 95\% Confidence Interval of the Difference } \\
\cline { 6 - 7 } & & & & Lower & Upper \\
\hline Type of school & 22.584 & 19 & .000 & 1.850 & 1.68 & 2.02 \\
Language competencies & 4.937 & 19 & .000 & 14.53846 & 8.3749 & 20.7020 \\
\hline
\end{tabular}

The P-Value is greater than 0.00 and therefore the null hypothesis should be rejected; there is a significant influence of type of school on the language competencies.

\section{Conclusion}

Based on the findings there exist significant differences in performance of languages between children attending schools in rural areas and those in urban areas. Lower participation in education and poorer educational outcomes in rural areas result from a combination of factors. On the demand side, children in rural areas may have less interest in school, more alternative demands on their time and less support from the home. These difficulties are compounded by supply-side inequalities, which provide a poorer education service for rural children.

The upgrading of infrastructure in poorer schools, the present education policy tends to treat all schools as being "the same". The same outcomes are expected from schools that operate under very different circumstances, and this is simply not realistic. Schools are not the same, particularly in terms of social, economic and linguistic conditions. We need to accept that equal treatment of learners from unequal backgrounds may give the appearance of treating everyone fairly, but it is likely to maintain inequality. Equal treatment cannot, under such circumstances, bring equal opportunities, let alone equal outcomes.

\section{References}

Brodie, K., Lelliott, A., \& Davis, H. (2002). Forms and substance in learner-centred teaching: teachers' take-up from an in-service programme in South Africa. Teaching and Teacher Education 18(5): 541-559.

Hedges, John (2002). 'The importance of posting and interaction with the education bureaucracy in becoming a teacher in Ghana' International Journal of Educational Development, 22, 353-366.

Hoff, E. (2003b). The specificity of environmental influence: Socioeconomic status affects early development via maternal speech. Child Development, 74, 1368-1378.

Mugenda, O. \& Mugenda, A. (2003) Research Methods: Qualitative and Quantitative Approaches. Nairobi: Acts Press.

Mungai, A. (2002). Growing up in Kenya. Rural Schooling and Girls. New York: Peter Lang.

Neuman, S.B. 2001. Essay Book Review: The role of knowledge in early literacy.

Reading Research Quarterly 36 (4): 468-75.

Snow, C.E., \& D.K. Dickinson. 1991. Skills that aren't basic in a new conception of literacy. In Literate systems and individual lives: Perspectives on literacy and schooling, eds. A. Purves \& E. Jennings. Albany: State University of New York (SUNY) Press.

Taylor, Peter and Mulhall, Abigail (2001) 'Linking learning environments through agricultural experience- enhancing the learning process in rural primary schools'. International Journal of Educational Development, 21, 135-148. 